\title{
Drone-Mounted Ultrawideband Radar for Retrieval of Snowpack Properties
}

\author{
Rolf Ole Rydeng Jenssen ${ }^{\circledR}$, Markus Eckerstorfer, and Svein Jacobsen, Senior Member, IEEE
}

\begin{abstract}
Extracting snowpack parameters from snow cover on sea ice or land is a time-consuming and potentially high-risk task. Moreover, deriving such parameters by manually digging a snow pit evidently yields low area coverage. We, therefore, propose a practical solution to this problem by mounting an ultrawideband radar system onto an unmanned aerial vehicle (UAV) to obtain information such as snowpack depth, density, and stratigraphy in order to increase personnel safety and extend coverage area. In this paper, we describe the development of radar system hardware and its mounting onto a UAV, as well as initial tests with this radar as a snow measuring device. Preliminary results from both ground and airborne testing show that the radar system is capable of obtaining snow depth information that corresponds well to in situ validation data with a correlation of 0.87 . The radar system also works well while mounted on a UAV platform with little additional signal noise from vibrational and translatory movements.
\end{abstract}

Index Terms-Snow, stratigraphy, ultrawideband (UWB) radar, unmanned aerial vehicle (UAV).

\section{INTRODUCTION}

$\mathbf{T}$ HE use of ultrawideband (UWB) radars has expanded tremendously in recent years [1]. Most applications involve subsurface sensing or high-resolution object detection. UWB systems that operate in the gigahertz band have penetration capabilities from which complex stratigraphical information can be extracted.

Previous studies show that UWB radar systems are capable of measuring snow depth and even more detailed stratigraphy with high accuracy. For instance, an $8-18-\mathrm{GHz}$ frequencymodulated continuous wave (FMCW) radar system was found to produce stratigraphic snow information with a correlation coefficient of 0.92 relative to in situ depth measurements

Manuscript received June 2, 2018; revised October 31, 2018; accepted December 31, 2018. This work was supported in part by the Center for Integrated Remote Sensing and Forecasting for Arctic Operations (CIRFA) partners and in part by the Research Council of Norway under Grant 237906. The work of M. Eckerstorfer was supported by the ESA Prodex Project DebriSAR under Grant C4000122520. The Associate Editor coordinating the review process for this paper was Christoph Baer. (Corresponding author: Rolf Ole Rydeng Jenssen.)

R. O. R. Jenssen and S. Jacobsen are with the University of Troms $\emptyset$ - The Arctic University of Norway, 9019 Troms $\varnothing$, Norway, also with the Norut Northern Research Institute, 9019 Troms $\emptyset$, Norway, and also with the Center for Integrated Remote Sensing and Forecasting for Arctic Operations, 9019 Troms $\emptyset$, Norway (e-mail: rolf-ole.r.jenssen@uit.no).

M. Eckerstorfer is with the Norut Northern Research Institute, 9019 Troms $\varnothing$, Norway.

Color versions of one or more of the figures in this paper are available online at http://ieeexplore.ieee.org.

Digital Object Identifier 10.1109/TIM.2019.2893043

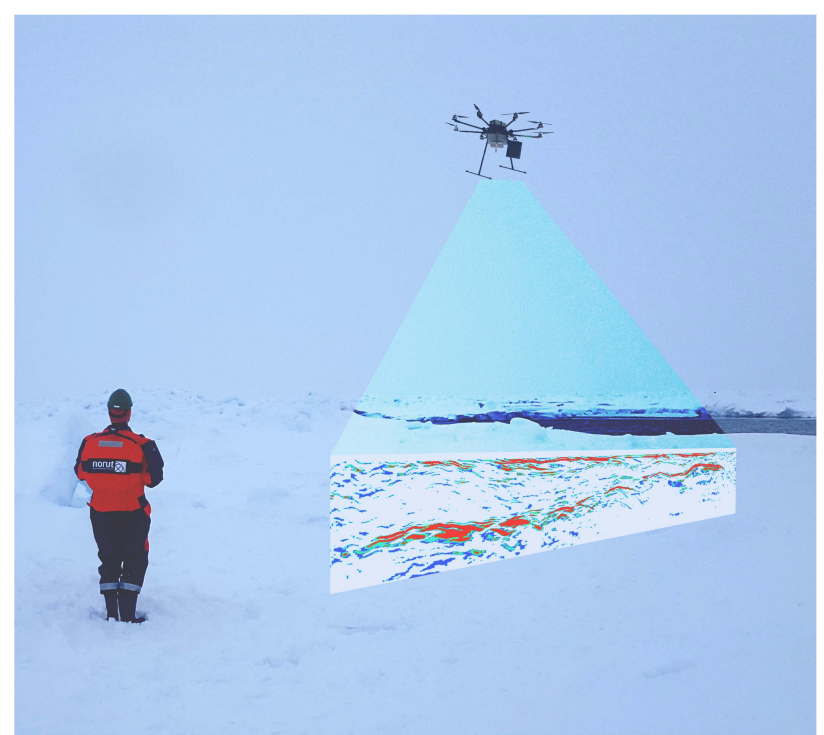

Fig. 1. Illustration of UWiBaSS snow depth measurement on sea ice.

up to snow depths of $30 \mathrm{~cm} \mathrm{[2],} \mathrm{while} \mathrm{other} \mathrm{studies} \mathrm{show}$ similar correlations: 0.86 [3] and 0.78 [4]. A recent study demonstrates a lightweight FMCW $\mathrm{Ku}$-band (14-16 GHz) radar for snowpack remote sensing [5]. In addition, a gated step-frequency ground penetrating radar (GPR), operating in the $0.5-3-\mathrm{GHz}$ range, enables snow and ice measuring capabilities to a depth of $11 \mathrm{~m}$ [6]. Moreover, radar systems are also capable of measuring snow depth while mounted on aircrafts revealing a correlation with in situ measured snow depth of 0.88 [7], and other systems demonstrate snow depth interface detection [8], or even both snow and ice depth interface detection [9]. Other authors have reported establishment of design parameters for an unmanned aerial vehicle (UAV)-mounted radar intended for snow parameter retrieval [10], with a recommended operating frequency inthe 1.5-4.5-GHz band. Furthermore, a number of other research groups have described UWB radars for UAV mounting, where the applications range from detection of ground targets such as cars, humans [11], [12], and ships [13], as well as topographic mapping [14]. In addition, investigations of UAV-mounted GPR [15] for detection of buried objects such as landmines [16] and other high scattering targets [17] have previously been examined. Nevertheless, ground penetrating radar systems with strict weight and compatibility requirements for UAV mounting, while still having the bandwidth to resolve complex snow stratigraphy and penetration through dense snow and ice 
down to the ground have, to the best of our knowledge, not been published in the literature.

The UWB snow sounder (UWiBaSS) discussed in this paper is a ground penetrating radar system developed for dronemounted operations. The radar system was designed with a focus on low payload weight to fulfill UAV mounting and high-range resolution requirements for snow measurements, contributing to the relatively new field of UAV-mounted instrumentation. The UWiBaSS will enable autonomous, drone-based measurements of snow-cover over large and hardto-reach regions. Retrieving snow cover information (e.g., depth, stratigraphy, and volume) is a challenging task for several different fields of use. Applications include avalanche risk analysis, snow water equivalent (SWE) estimation for hydropower companies, and snow measurements on sea ice for environmental research [18]. The UWiBaSS has the potential to provide stratigraphic information about the snowpack that could be useful for further analysis of the cryosphere. Initial tests from a ground-mounted rig covering a small scan range $(\approx 3.5 \mathrm{~m})$ were conducted in 2016 and the correlation with in situ measured stratigraphy was found to be 0.97 [19]. However, this version of the system used antennas with low directivity which are not suitable for UAV mounting and moderate flight altitudes. Fig. 1 illustrates the usage of the radar system, measuring snow depth on sea ice.

This paper will concentrate on the measurement concept and initial validation of the UWB radar system. Testing includes both ground-based measurements where the results are correlated with in situ measurements and an airborne test flight over snow-covered sea-ice.

\section{RADAR System DEVElopment}

Technically, the radar system consists of an $m$ :sequence UWB radar sensor [20], custom-designed spiral and Vivaldi antennas, a single board acquisition computer with processing software, and an octocopter UAV with autonomous flying capabilities specially built for the application.

Key design parameters of our radar system include weight, range resolution, unambiguous range, and incident power at the target. The latter parameter depends on antenna gain, height above target, and radar system amplifier parameters. This section will go through the basic theory of the design considerations as well as the development of the radar system components.

The maximum range in which a target can be detected is restricted by the observation time window length. The unambiguous range in a given medium for an $m$ :sequence radar $R_{0}$ can be expressed as [21]

$$
R_{0}=\frac{\frac{c}{\sqrt{\epsilon_{r}}}\left(2^{m}-1\right)}{2 f_{c}}
$$

where $c$ is the propagation velocity in free space, $\epsilon_{r}$ is the relative permittivity of the propagation medium, $m$ is the order of the $m$ :sequence shift register, and $f_{c}$ is the $m$ :sequence clock frequency.

The unambiguous range is an important parameter as it describes the maximum height (over ground or ice) the platform can fly at and still measure the snow cover between sensor and ground.

The radar system also needs an adequate range resolution to separate internal layers in the snow. Here, we will focus on the actual measured pulsewidth from a test measurement of a metal target [19]. This is done to take into account all factors that influence the range resolution including the transmitted waveform, antennas, and the postprocessing methods.

Theoretically, the range resolution of a pulse compression radar system is given by [22]

$$
\Delta r=\frac{c}{2 B} \frac{1}{\sqrt{\epsilon_{r}}}
$$

where $B$ is the effective bandwidth of the radar transmitter and receiver. Equation (2) shows that the radar system bandwidth is a fundamental parameter of the range resolution, and, theoretically, the only attribute that can be modified to improve the range resolution significantly. The bandwidth of $m$ :sequence signals is described in (5). For high dielectric media, $\epsilon_{r}$ also has a marked impact on the range resolution. In radar applications, additional factors such as pulse compression, Fourier domain windowing, and image processing methods affect the radar system output range resolution, however, only to a minor degree.

\section{A. Radar Equation for Flat Surfaces}

In the special case of flat surface targets, such as planar homogeneous snow cover, the radar equation must be rewritten. To apply this special case, the flat surface must dimensionally be at least two Fresnel zones across. The radius $F_{n}$ of Fresnel zone $n$ is defined as [23]

$$
F_{n}=\frac{n \pi}{2} \sqrt{\frac{R \lambda}{2}}
$$

where $n$ is the Fresnel zone number, $R$ is the distance to the target, and $\lambda$ is the wavelength of the transmitted signal.

If the target satisfies this requirement, the receiver essentially sees an image of the transmitter at a distance of $2 R$. In the case of our radar system, (3) results in a minimum required radius of the flat target of $3.07 \mathrm{~m}$ when the distance to the target is set to the unambiguous range, and using the longest wavelength within the bandwidth of the radar. This configuration can be modeled as a point-to-point communication link (i.e., $2 R^{2}$ dependence instead of $R^{4}$ ). For this special case, the radar equation for received power $P_{r}$ becomes [23]

$$
P_{r}=\frac{P_{t} G^{2} \lambda^{2} \Gamma}{(4 \pi)^{2}(2 R)^{2} F}
$$

where each parameter is defined in Table I.

The equation shows that the received power decreases with $1 /\left(2 R^{2}\right)$ for flat surface targets, which means that increasingly distant targets become significantly harder to detect. However, the received power does not decrease as fast compared to point targets $\left(1 / R^{4}\right)$. Nevertheless, this still is an important limiting factor for any radar system. 
TABLE I

RADAR EQUATION PARAMETERS

\begin{tabular}{l|l}
\hline Parameter & Description \\
\hline$P_{r}$ & Received Power \\
$P_{t}$ & Transmitted Power \\
$G$ & Gain of transmitting and receiving antenna \\
$\lambda$ & Wavelength of transmitted signal \\
$F$ & Pattern propagation factor (total loss factor) \\
$\Gamma$ & Fresnel power reflection coefficient \\
$R$ & Distance from the transmitter to the target (range) \\
\hline
\end{tabular}

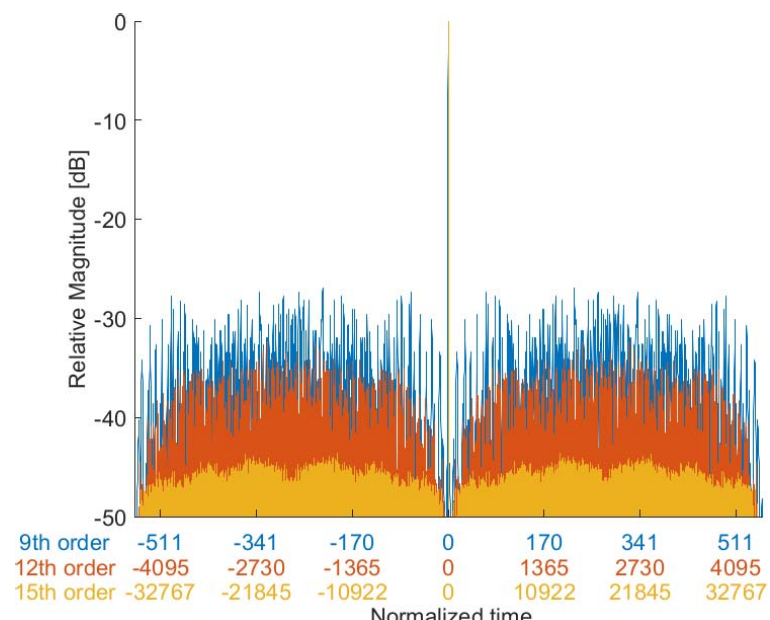

Fig. 2. Match filter output for 9th (blue), 12th (red), and 15th (yellow) order shift registers. The time axis is normalized with respect to the register bit lengths. The unit is therefore in bits.

\section{B. Radar Sensor and Waveform}

The most suitable commercial radar hardware for our application was found to be the ILMsens $m$ :explore transceiver system. This was mainly due to strict weight requirements as well as a suitable UWB waveform. This newly developed commercial " $m$ :sequence" UWB sensor has several desirable characteristics concerning high-resolution radar imaging. ${ }^{1}$ One central attribute is the ability to replace impulse waveforms with signals which spread their energy equally over a long time, hence reducing the signal peak power. This reduction in instantaneous signal level leads to low-cost RF circuit integration [24]. Since this type of waveform does not require a changing frequency (e.g., sweeping oscillator), a more stable system time base is achieved. Moreover, for active components, the nonlinear distortion will also be reduced compared to pulse excitation due to the low peak power of $m$ :sequence excitation [25].

The basic concept of signal generation is to produce a binary sequence from a fast shift register controlled by a system clock. The $m$ :sequence has a short autocorrelation function resulting in a flat spectrum over a large bandwidth.

The bandwidth of the signal can with some simplification be related to one parameter, the system clock frequency $f_{c}$ [21]

$$
B \approx \frac{f_{c}}{2}[\mathrm{~Hz}]
$$

\footnotetext{
${ }^{1}$ Visit the ILMsens website at: https://www.uwb-shop.com/products/ m-explore/
}

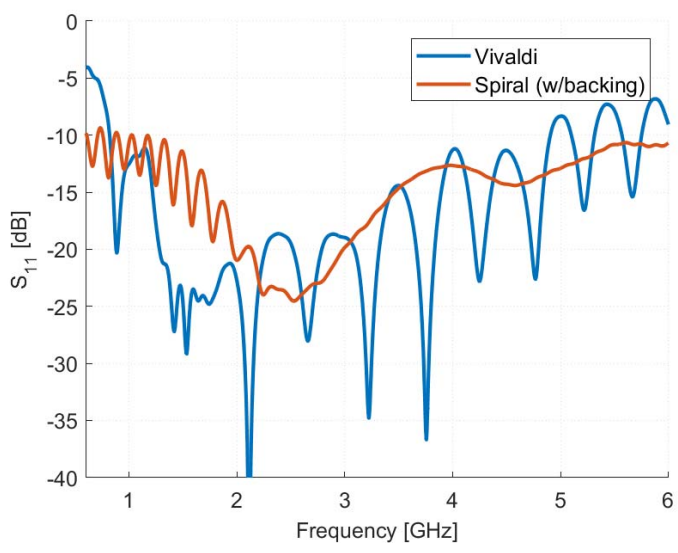

(a)

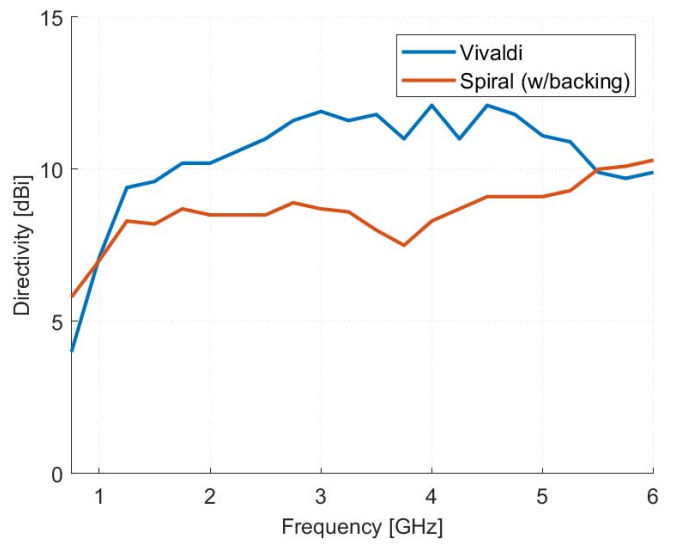

(b)

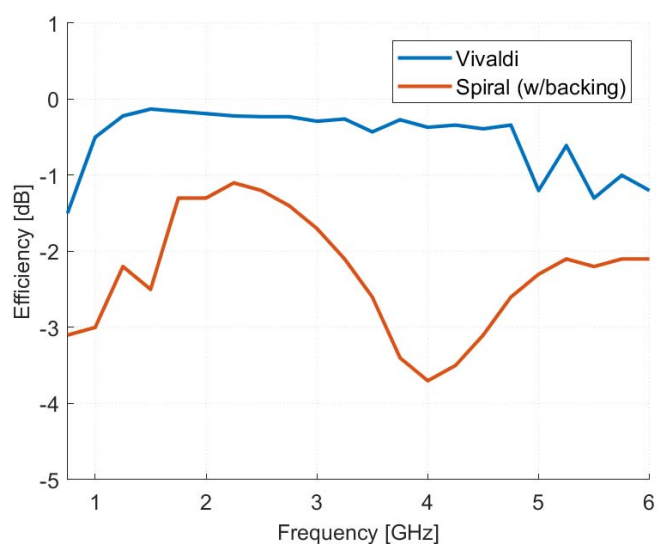

(c)

Fig. 3. Simulated antenna parameters. (a) Simulated $S_{11}$ return loss for Vivaldi antenna and Archimedean spiral antenna with cavity backing. (b) Simulated directivity for Vivaldi antenna and Archimedean spiral antenna with cavity backing. (c) Simulated efficiency for Vivaldi antenna and Archimedean spiral antenna with cavity backing.

The $m$ :sequence waveform has acceptable sidelobe performance after match filter processing where the sidelobes decrease with increasing shift registry length. Fig. 2 shows the match filter autocorrelation function for the three available radar sensor models. The length of the shift registry also affects the unambiguous range of the radar as each bit represents a range bin in the processed scan. If the shift register has a size of, say, $m$ bits, then the maximal length (i.e., period) 

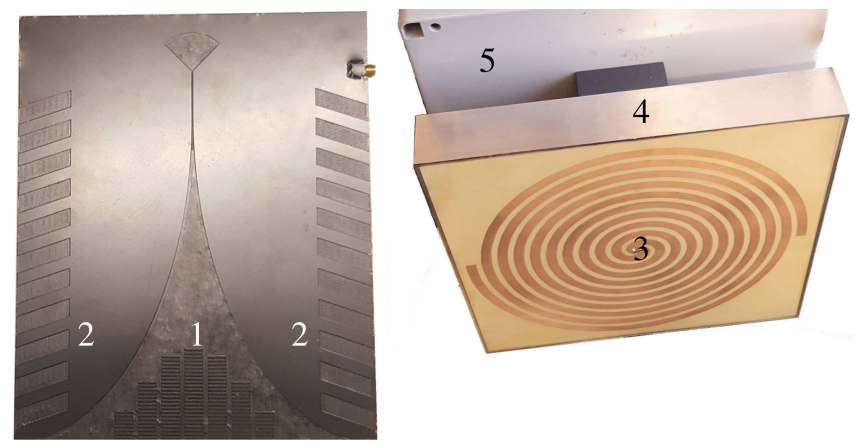

(a)

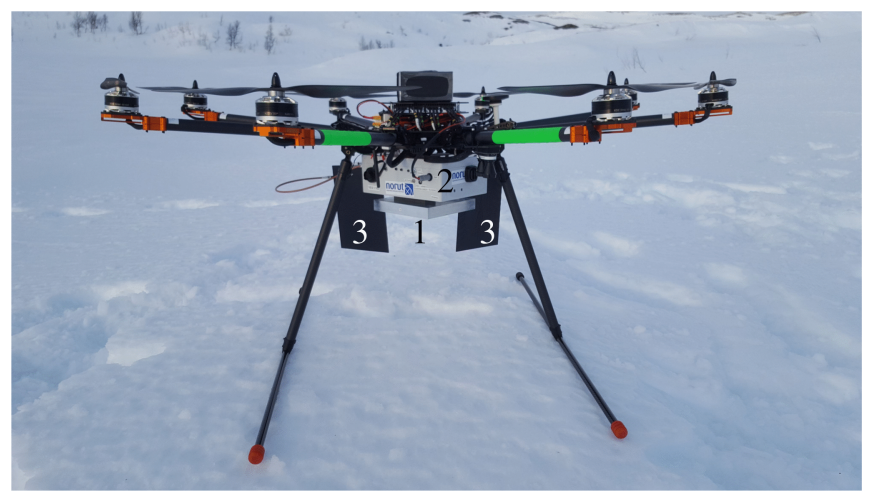

(b)

Fig. 4. (a) Vivaldi antenna prototype with printed lens (1) and inserted slits (2) and Archimedean spiral antenna (3) with cavity backing (4) mounted below radar box (5). The spiral is superimposed on the image as it is not visible from the outside. (b) Radar system mounted on an octocopter drone (Kraken), with the transmitting spiral antenna (1) mounted below the radar box (2), and the two receiving Vivaldi antennas (3) in $90^{\circ}$ offset on the sides.

is $2^{m}-1$. In the air, and with a registry length of $m=9$ (used in the UWiBaSS), this translates to a maximum two-way travel length of $5.75 \mathrm{~m}$ based on (1).

\section{Antenna Development}

The system currently in use utilizes two different antenna types: a planar Archimedean spiral antenna with circular polarization, used as the transmitting antenna, and two Vivaldi antennas as receiving antennas; the latter two mounted in $90^{\circ}$ offset to each other to produce two linear receiving polarizations. This configuration enables hybrid polarization reception [26], thus potentially increasing signal-to-noise ratio (SNR) when combining the two receiving channels, or finding specific characteristics when looking at the polarization of targets. Common to both antenna types is the ease of production with printed circuit board (PCB) etching or milling. Fig. 3 shows the simulated antenna parameters of the two antennas in question. Full-wave simulations were performed using CST Microwave Studio ${ }^{2}$ commercial software, showing that the two antenna types have different performance characteristics, especially when comparing directivity and efficiency.

The Archimedean spiral antenna [27] has peak radiation perpendicular to the surface of the spiral in both directions.

\footnotetext{
${ }^{2}$ Visit the CST website at: https://www.cst.com/products/cstmws
}

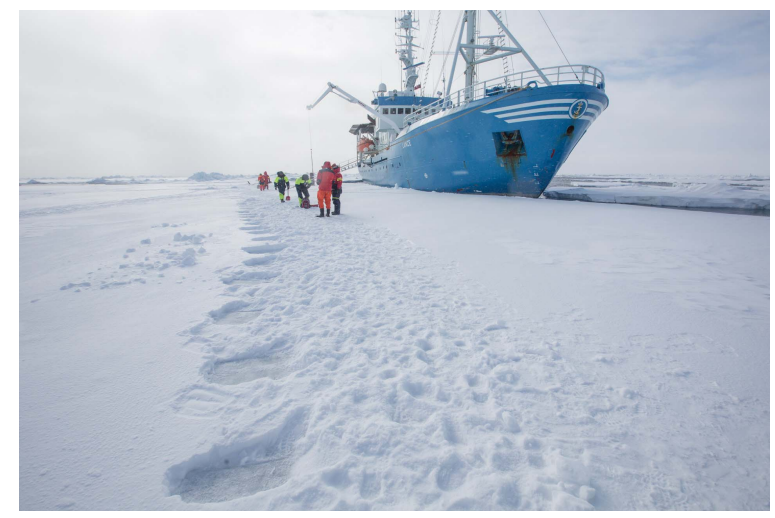

Fig. 5. 20-m transect on Arctic sea ice, where in situ snow depth was measured with $1-\mathrm{m}$ spacing.

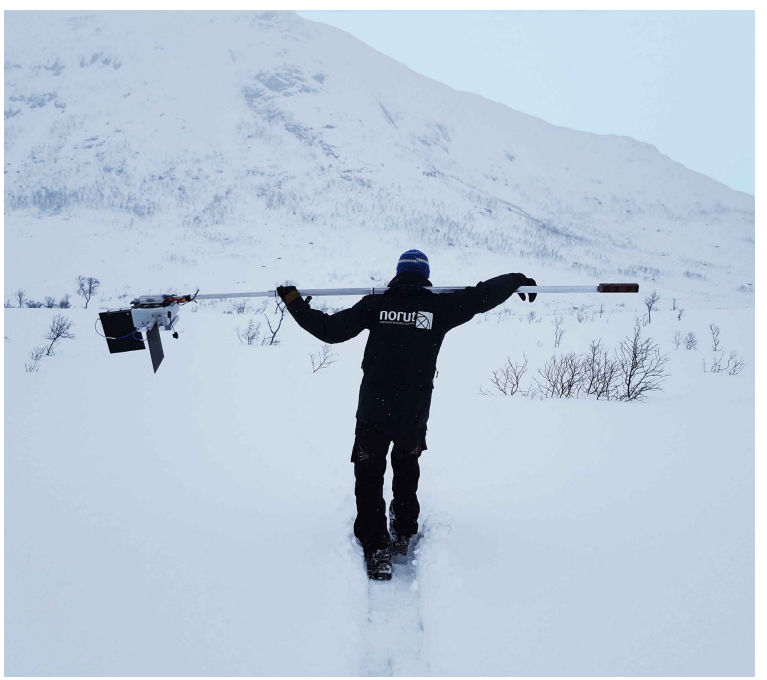

Fig. 6. 100-m transect at Kattfjordeidet, where in situ snow depth was measured with $1-\mathrm{m}$ spacing. The radar is mounted on the left side of the boom with a counterweight on the right side.

Therefore, a cavity with absorbing material of type MF-114 (2.5 $\mathrm{cm}$ thickness) was mounted on the back of the antenna [Fig. 4(a)] to avoid multipath standing waves and interference in the UAV systems above. Spiral antennas are capable of nearly frequency-independent input impedance and gain over a wide bandwidth [28]. However, when radiating a wideband signal, the dispersive properties of the antenna cause distortion. This distortion can be described by the impulse response of the spiral antenna which is a chirp [28]. Thus, a dechirping procedure is implemented in signal postprocessing to account for the varying antenna group delay across the frequency band.

\section{Vivaldi Antenna Modifications/Improvements}

The main goal of the Vivaldi antenna modifications was to maximize directivity and reduce antenna physical area without loss of bandwidth. Vivaldi antennas are widely used in UWB systems much due to the ease of production through PCB etching or milling technology [29].

\footnotetext{
${ }^{3}$ Visit the Laird website at: https://www.lairdtech.com/solutions/rfmicrowave-absorption
} 


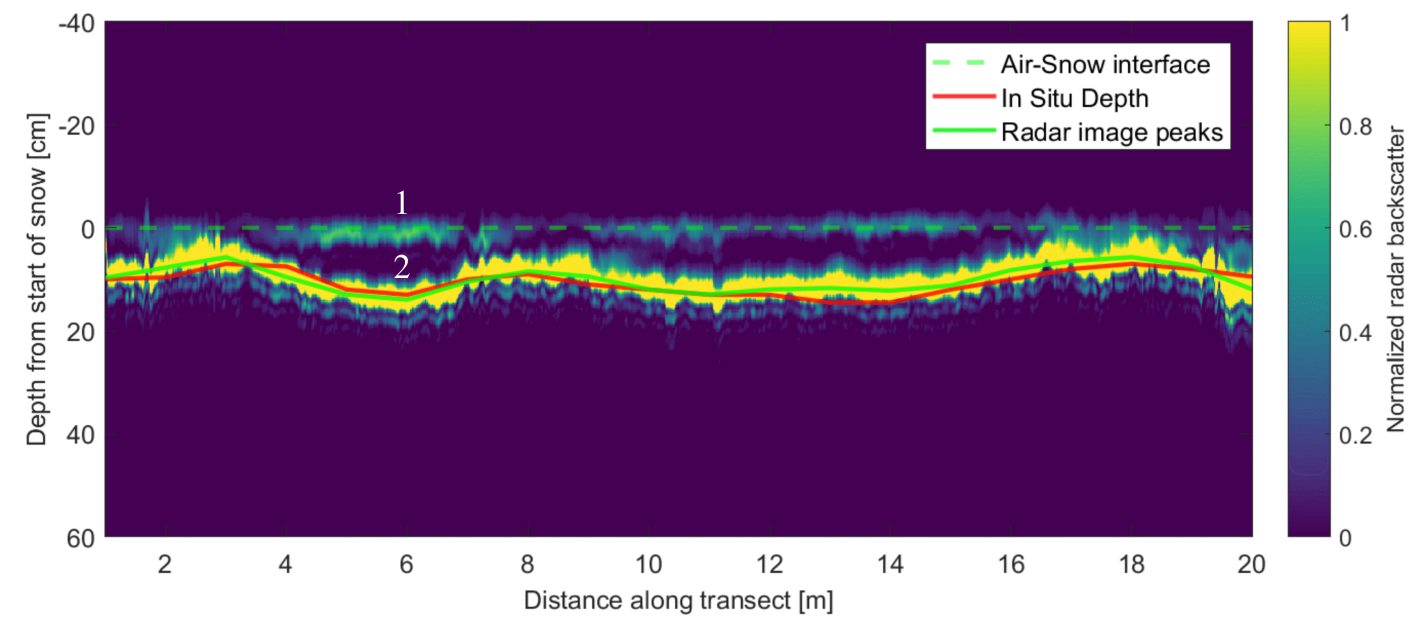

Fig. 7. In situ measured snow depth and radar image for a 20-m transect taken on Arctic sea ice. This was dry, porous snow resulting in a weak return at the air-snow interface (1), with brine at the snow-ice interface (2). Mean density: $\rho=0.29 \mathrm{~kg} / \mathrm{m}^{3}$ and dielectric constant: $\epsilon=1.55$ (6).

1) Printed Lens in Aperture: Research on printed lenses in the Vivaldi antenna aperture was conducted by Avdushin et al. [29] where it was found that the use of printed lens leads to increased gain and reduced sidelobe levels. The lens was fabricated in the same manner in our antennas only modified to accommodate the larger bandwidth requirements for the UWiBaSS.

2) Inserted Slits: The use of inserted slits in tapered slot antennas was proposed by Kim and Choi [30] where it was shown that a significant increase in bandwidth was obtained with implemented slits of adequate size compared to the basic tapered slot antenna. A similar design was implemented on the Vivaldi antennas in order to obtain the required bandwidth while keeping a minimum antenna area. Fig. 4(a) shows the prototype antenna with both slits and printed lens patches.

Table II describes the key characteristics of the radar system. Note that these values are the actual performance of the entire system. This means that the bandwidth is the combined bandwidth of the sensor and the antennas. The resolution is measured by the full-width at half-maximum distance of a processed radar pulse [19]. Fig. 4(b) shows the radar system mounted on an octocopter drone.

\section{E. UAV Description}

The UAV used to carry the UWiBaSS is a purposebuilt octocopter called "Kraken." The "Kraken" octocopter can lift a maximum payload of $8 \mathrm{~kg}$. Each of the eight engines (KDE 5215XF-435) has a maximum rated thrust of $8.45 \mathrm{~kg}$ using $46 \mathrm{~cm} \times 15.5 \mathrm{~cm}$ propellers. "Kraken" uses six cell Li-Pol batteries (currently at $30 \mathrm{Ahr}$ ) and Hacker Master Mezon 90 engine speed control (ESC). For navigation and control, a "pixhawk2" autopilot running "arducopter" is used. A SF11 laser rangefinder, mounted on one of the eight arms, accurately measures the distance to the ground. It is set up with a "Here+" real-time kinematic (RTK)

\footnotetext{
${ }^{4}$ For more information about SF11 visit: https://lightware.co.za/products/ sf11-c-120-m
}

TABLE II

UWIBASS KEY CHARACTERISTICS

\begin{tabular}{ll}
\hline Attribute & Value \\
\hline Signal generation & UWB Pseudo noise \\
System bandwidth & $5.05 \mathrm{GHz}(0.95-6)$ \\
Range resolution & $\approx 5 \mathrm{~cm}$ \\
m-sequence clock frequency & $13.312 \mathrm{GHz}$ \\
Measurement rate & $32 \mathrm{~Hz}(\mathrm{max} 1000 \mathrm{~Hz})$ \\
MLBS order & $9(511$ range bins $)$ \\
Nominal output power & $-7 \mathrm{dBm}$ \\
Unambiguous range in air & $5.75 \mathrm{~m}$ \\
Total power consumption & $\approx 12.7 \mathrm{~W}$ (Radar $\approx 9 \mathrm{~W})$ \\
Weight & $\approx 4 \mathrm{~kg}$ \\
\hline Transmitter & \\
\hline No high voltage peaks, low field strength operation \\
Custom made planar spiral antenna \\
\hline Receiver \\
\hline Continuous, synchronous sub-sampling operation \\
Custom made Vivaldi Antenna with printed lens \\
\hline
\end{tabular}

global positioning system (GPS), ${ }^{5}$ providing much more accurate position estimates than regular GPS. The positioning system has relative and absolute accuracy below $10 \mathrm{~cm}$ and $1 \mathrm{~m}$, respectively, in single-channel mode, given the distance to the base station is less than $20 \mathrm{~km}$. This also provides autonomous flights that have been tested at above ground altitudes as low as $1 \mathrm{~m}$. "Kraken" can be set up with an "MBR 144" radio system to operate a $15-\mathrm{Mb} / \mathrm{s}$ radio link, which enables near real-time processing of the radar image.

\section{In Situ MethodS}

The tools used to measure in situ snow depth and density were a depth measurement probe (avalanche probe) and a volumetric density cutter [31]. The depth measurement probe had a centimeter-scale accuracy. Snowpack stratigraphy was assessed in manual snowpits. If we assume the liquid water (and salinity) content to be negligible, then the dielectric constant can be assumed to be real-valued and only dependent on density.

${ }^{5}$ For more information about "Here+" RTK GPS visit: http://ardupilot.org/copter/docs/common-here-plus-gps.html 


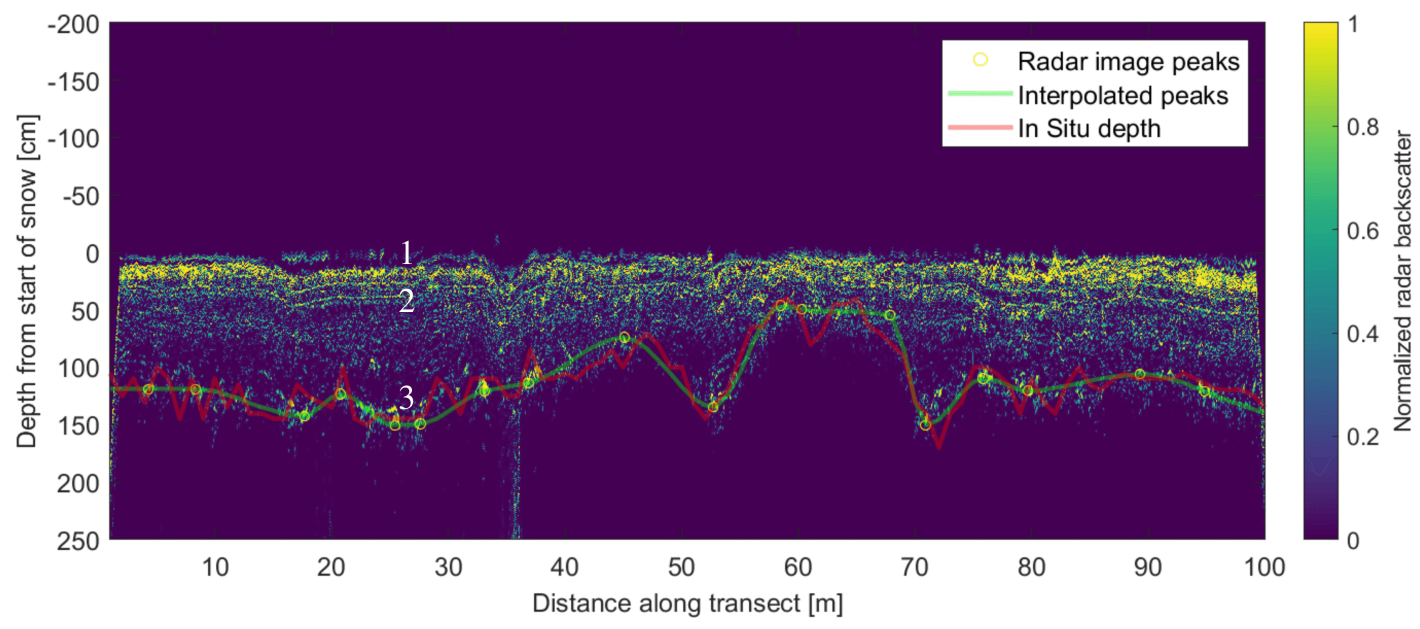

(a)

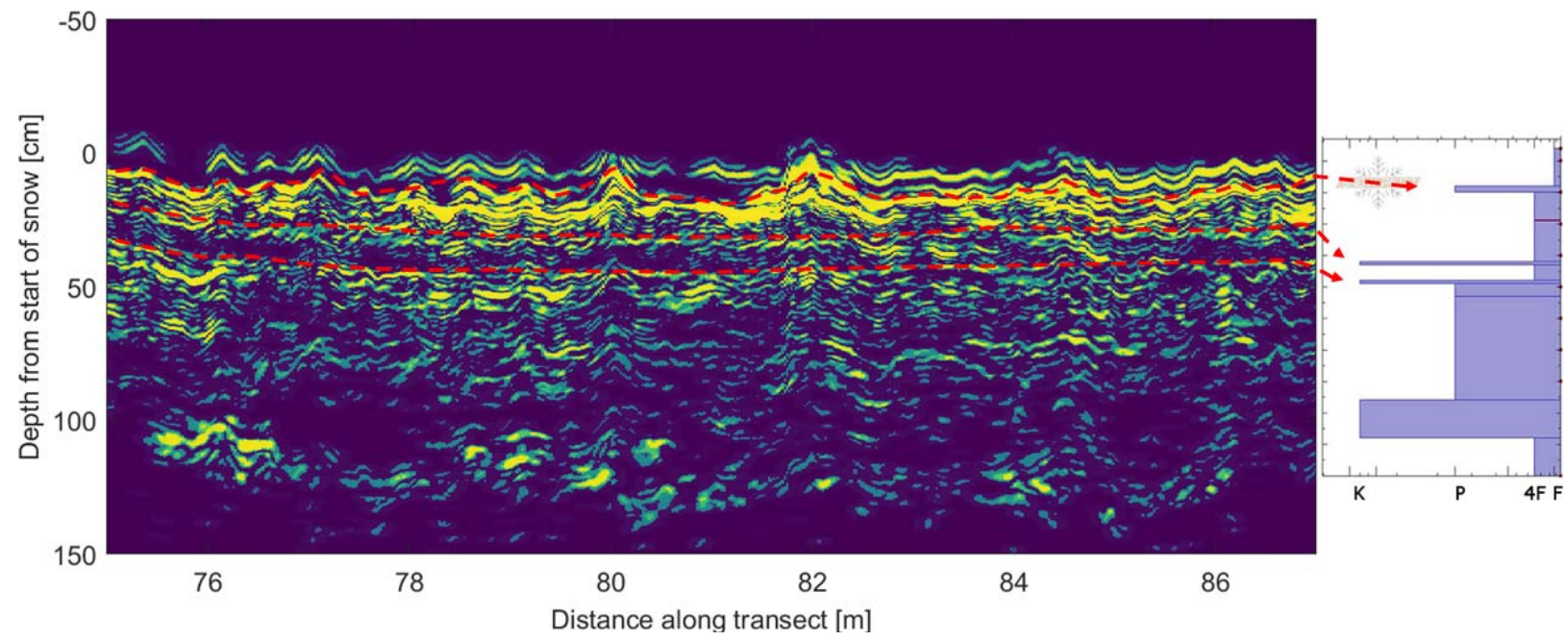

(b)

Fig. 8. (a) Radar image from Kattfjordeidet. In situ snow depth and radar image for a 100-m transect taken in Kattfjordeidet, with the air-snow interface at $0 \mathrm{~cm}$ (1), internal hard snow layers at $25 \mathrm{~cm}$ (2), and the snow-ground interface between 60 and $170 \mathrm{~cm}$ (3). This was wet snow with approximately $3 \%$ liquid water content. Mean density: $0: 43 \mathrm{~kg} / \mathrm{m}^{3}$ and dielectric constant $=2: 57$ (7). (b) Cropped section from (a) compared with in situ stratigraphy. Red arrows mark the three first layers of the snowpack. Layer hardness is denoted as $\mathrm{K}=$ knife, $\mathrm{P}=$ pen, $4 \mathrm{~F}=$ four fingers, and $\mathrm{F}=$ fist [33].

The dielectric constant can be written as [32]

$$
\epsilon_{d}^{\prime}=1+1.91 \rho_{d}
$$

where $\epsilon_{d}^{\prime}$ is the real part of the dielectric constant and $\rho_{d}$ is the density of the snow in $\left[\mathrm{g} / \mathrm{cm}^{3}\right]$.

Considering cases of significant amounts of liquid water in the snowpack (approximately from $2 \%$ up to $10 \%$ ), the real part of the dielectric constant can be calculated as [32]

$$
\epsilon_{d}^{\prime}=1+2 \rho_{d}+23.5 W_{u}
$$

where $W_{u}$ is the wetness by volume fraction.

\section{Ground Based Sensor VAlidation}

In this section, we study two different measurement scenarios for system validation, both supported by detailed in situ measurements of snow depth, density, and in one case, stratigraphy. Section $\mathrm{V}$ presents an airborne test flight measuring snow-covered sea ice.
TABLE III

DEPTH CORRELATION

\begin{tabular}{l|ll}
\hline Quantity/Area & Arctic sea & Kattfjordeidet \\
\hline Max in situ depth & $14.5 \mathrm{~cm}$ & $170 \mathrm{~cm}$ \\
RMSE (\% from in situ) & $1.16 \mathrm{~cm}(8 \%)$ & $13.1 \mathrm{~cm}(8 \%)$ \\
Correlation coeff. & $0.89 \pm 0.01$ & $0.87 \pm 0.07$ \\
\hline
\end{tabular}

\section{A. Measurement Scenarios}

A 20-m transect on Arctic sea ice (LAT: 80.1710189 LONG: 6.9864596, Date: May 22, 2017) was used as one of the sites to perform sensor validation. The snow cover is shown in Fig. 5 and was approximately $10 \mathrm{~cm}$ of dry snow with approximately $1 \mathrm{~cm}$ of briny snow on the bottom of the snowpack (superstrate on the sea ice).

In addition, a 100-m transect at Kattfjordeidet (Troms county, Norway. LAT: 69.655705 LONG: 18.550190, Date: May 8, 2017) was chosen as another site to perform sensor 
validation. The relatively deep snow cover (up to $170 \mathrm{~cm}$ ), shown in Fig. 6, was particularly challenging that day (wet snow with approximately $3 \%$ liquid water), as the penetration depth in snow decreases significantly for wet snow [34]. The transect was square shaped with 25 -m sides. At each corner, a metal reflector was placed as a calibration point to position the radar traces. These parts of the transect, where we stood still with the radar platform, have been removed from the data sets. Snow depth was measured at 1-m intervals and a snowpit was dug in the middle of the transect to analyze density, liquid water content, and stratigraphy.

\section{B. Data Processing}

With low antenna isolation due to UAV mounting restrictions, the main focus of the processing is to remove antenna crosstalk and improve SNR. The first technique applied to the radar data is match filter processing, performed on each received A-scan by cross-correlating the received signal with a locally stored sequence, matching the transmitted sequence before it is stored locally in the radar control computer hard drive. The postprocessing procedure involves subtracting a reference measurement, normally a measurement from a flight well above the unambiguous range of the radar, or subtracting the slow-time mean of the entire B-scan if no reference measurement is available. Dispersion correction to account for the varying group delay of the spiral antenna is performed by rectifying the phase of the signal using a nonlinear least squares model of the phase [28]. More information about this method can also be found in [19]. By using an edge detection algorithm and circular shift of the fast-time vectors according to the edge position, we can flatten the first reflection (i.e., air-snow interface), thus reducing vibrational and fast varying altitude variations in the image. In addition, the fast-time vector is time-stretched at the air-snow interface and below to compensate for the reduced propagation velocity in the snow. In order to time stretch the fast time vector according to the change in propagation velocity in the snow, we need an estimate of the dielectric constant of the medium [21]. For this test, we only considered the real part of the dielectric constant (very low-medium absorption) and used the average of the in situ density measurements to estimate the dielectric constant amplitude. The two receiving channels can be combined to improve SNR or used in further processing steps to generate polarimetric parameters. However, to better assess the performance of the radar system in these initial tests, one channel was used as a first look at the test results.

\section{Depth Measurement Concordance}

In this section, we will look at GPR style images produced from the radar data. For comparison, the manually measured snow depth across the transect is overlaid on the images.

The resulting radar images show a strong correlation (see Table III) between in situ depth measurements and the ground (and ice) reflection below the snow (see Fig. 7 point 2). Prominent reflectors (at approximately $100 \mathrm{~cm}$ ) on the snowground interface in Fig. 8(a) are assumed to be rocks as the topography in the area contains some rock coverage. These eye-catching reflection points go through a cubic interpolation procedure to create a continuous interface to be compared with in situ measurements. This data set was selected to show how the system performs probing difficult snow conditions. Measurements on dry snow (Fig. 7) show significantly stronger snow-ground (or ice) interface and no internal layer structures as the snow cover was at a depth of maximum $14.5 \mathrm{~cm}$ and nearly homogeneous. Fig. 8(a), on the other hand, shows more complex internal structures with two hard layers at approximately $25 \mathrm{~cm}$. These thin, hard layers can be found in the in situ stratigraphy in Fig. 8(b). The hardness of the layers is recorded using the "hand hardness test" [33]. Note that the deepest hard layer in the in situ stratigraphy was not detected. This is due to high attenuation through the snow caused by the $3 \%$ liquid water content and/or variations between snow stratigraphy at the snow pit and radar transect.

\section{Airborne TESTING}

The test was conducted as an octocopter UAV flight with the UWiBaSS system mounted below. The intention was mainly to evaluate the system while airborne to see how it performed with the added mechanical movement of the octocopter. The test consisted of measuring snow depth and stratigraphy while the radar system was flown over Arctic sea ice covered with dry snow (LAT: 80.1707498 LONG: 6.9866582, Date: May 20, 2017). Only one flight was conducted with no in situ measurements to validate the measured snow depth due to harsh weather conditions and difficult accessibility. However, the varying snow depth (shown in Fig. 9) agrees well with how the snow was perceived when walking on the ice, as the ice had several ridges and other irregularities, while the snow had a flat cover. The radar data was processed in the same way as in Section IV, and the dielectric constant was estimated from density measurements taken on the same ice floe the preceding day. The distance axis in Fig. 9 is only an approximate distance as the UAV had errors in the GPS data due to the drifting of the ice floe. However, the UAV was moving in a relatively straight line across the ice floe. Thus, the distance is estimated from the average speed of the UAV. The ice surface was slightly wet with superimposed briny water, which might explain why no significant penetration into the ice was achieved. Note in Fig. 9(a) and (c) that the ice surface rises almost all the way up to the air-snow interface. This is assumed to be the start of a small ice ridge, which was visually detected further into the ice floe. Fig. 9(b) shows relatively constant snow thickness. Also, note scattering hyperbolas close to the center of the transect shown in Fig. 9(b). These are assumed to be small areas of brine-soaked snow on the ice surface.

\section{Discussion AND CONCLUSION}

Development and initial testing of the UWiBaSS radar system are presented in this paper. The test procedure consisted of three measurement scenarios. The first setup on Arctic sea ice was during conditions with dry and shallow snow $(10 \mathrm{~cm})$ which were easy to penetrate with the radar. The 


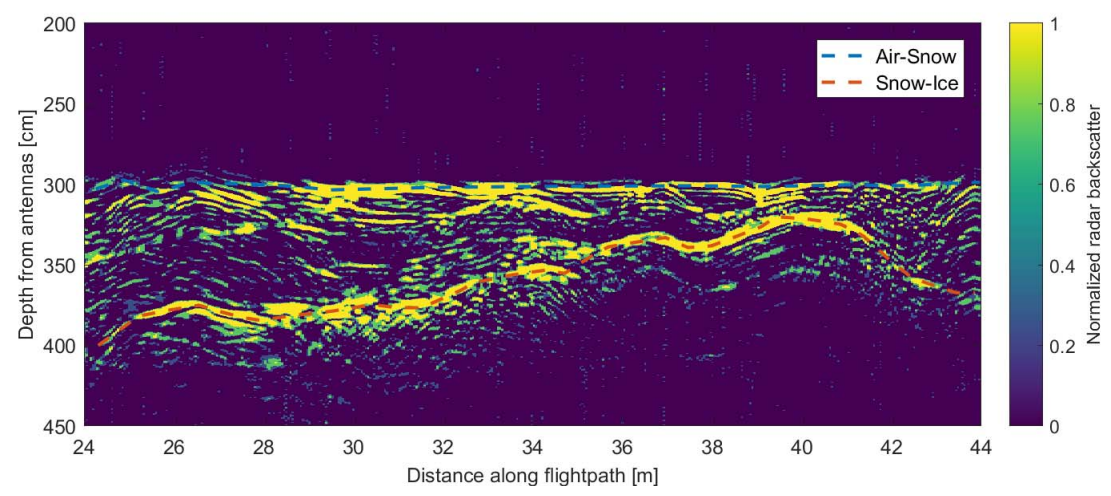

(a)

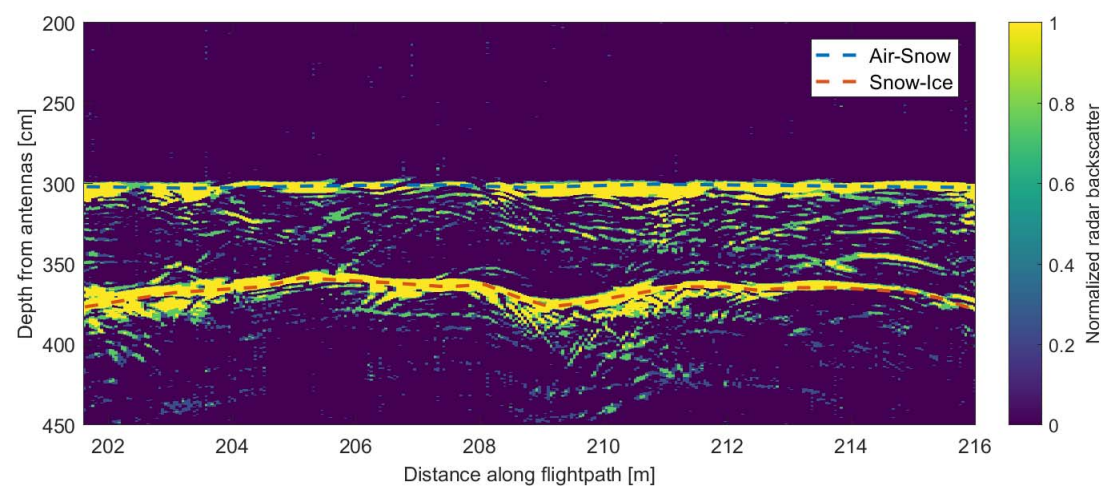

(b)

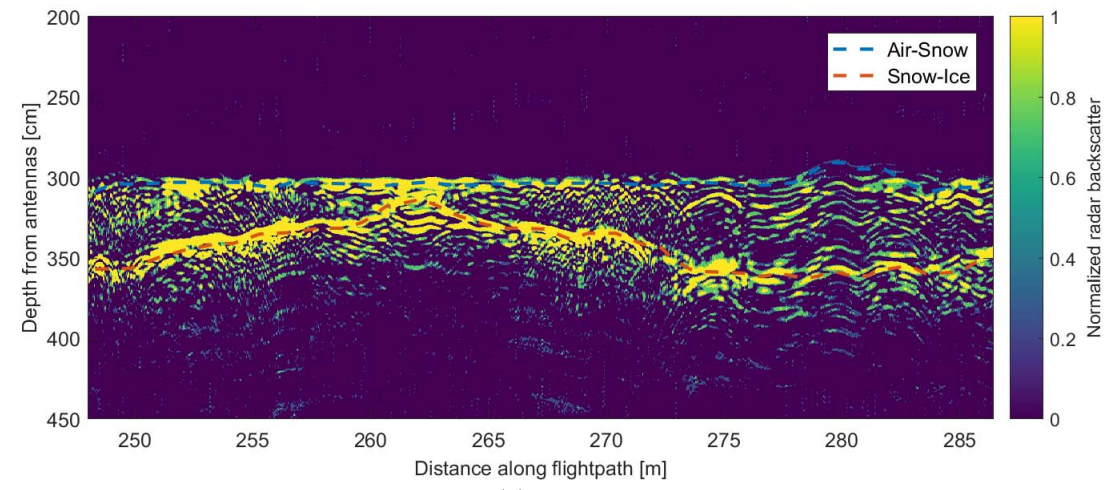

(c)

Fig. 9. Radar image of snow cover on Arctic sea ice with blue and red lines interpreting the air-snow $(\approx 300 \mathrm{~cm})$ and snow-ice $(\approx 300-400 \mathrm{~cm})$ interfaces. Mean density: $\rho=0.29 \mathrm{~kg} / \mathrm{m}^{3}$ and dielectric constant: $\epsilon=1.55$ (6). (a) Decreasing snow depth (ridge). (b) Constant snow depth. (c) Increasing snow depth (ridge).

results show a correlation coefficient of 0.89 and root-meansquare error (RMSE) of $1.16 \mathrm{~cm}$ (see Table III) compared to in situ snow depth measurements. The second scenario was far more challenging with snow depths up to $170 \mathrm{~cm}$ and as much as $3 \%$ liquid water content. Still, the radar system was able to measure the snow depth with a correlation coefficient of 0.87 and RMSE of $13.1 \mathrm{~cm}$. The radar system was also able to detect the most prominent layers in the snowpack [see Fig. 8(b)]. Hence, both setups resulted in an error of about $8 \%$ which is acceptable compared to other reported systems [2], [7], [18]. The third scenario was focused on testing the radar system while mounted on a UAV to detect potential challenges and signal dropout with added vibration and translatory movement of the radar platform. The resulting radar images from the test flight show similar responses from the snow with ground-based measurements. We can, thus, conclude that the UWiBaSS works well when mounted on an airborne platform. 
Overall, we conclude that the UWiBaSS radar performs according to specifications and has the potential to be a powerful snow measurement tool enabling UAV-mounted, large area snow coverage scanning.

Future work includes developing faster algorithms for radar data acquisition and further improvements on the design of the receiving and transmitting antennas. The retrieval of other snowpack parameters, such as density from UAV-mounted radars, is under investigation and initial results are promising. Furthermore, larger data sets relating in situ stratigraphy and radar response might give insight into the interpretation of the radar images.

\section{ACKNOWLEDGMENT}

The authors would like to thank K. Shaw and J. Yackel for collecting in situ data at the arctic sea transect during the INTPART Field School cruise. The INTPART Field School 2017 cruise was funded by the INTPART Arctic Field Summer Schools: Norway-Canada-USA collaboration (NFR project 261786/H30). They would also like to thank two anonymous reviewers for the comments and suggestions that improved this paper.

\section{REFERENCES}

[1] J. Sachs et al., "Noise Radar Design," Appl. Radio Electron., vol. 12, no. 1, pp. 79-88, 2013.

[2] H.-P. Marshall, M. Schneebeli, and G. Koh, "Snow stratigraphy measurements with high-frequency FMCW radar: Comparison with snow micro-penetrometer," Cold Regions Sci. Technol., vol. 47, nos. 1-2, pp. 108-117, 2007, doi: 10.1016/j.coldregions.2006.08.008.

[3] K. K. Singh et al., "Snow depth and snow layer interface estimation using Ground Penetrating Radar," Current Sci., vol. 100, no. 10, pp. 1532-1539, 2011.

[4] N. Yankielun, W. Rosenthal, and R. E. Davis, "Alpine snow depth measurements from aerial FMCW radar," Cold Regions Sci. Technol., vol. 40, nos. 1-2, pp. 123-134, 2004, doi: 10.1016/j.coldregions.2004.06.005.

[5] Y. Kim et al., "A $\mathrm{K}_{u}$-band CMOS FMCW radar transceiver for snowpack remote sensing," IEEE Trans. Microw. Theory Techn., vol. 66, no. 5, pp. 2480-2494, May 2018, doi: 10.1109/TMTT.2018.2799866.

[6] M. J. Oyan, S.-E. Hamran, L. Hanssen, T. Berger, and D. Plettemeier, "Ultrawideband gated step frequency ground-penetrating radar," IEEE Trans. Geosci. Remote Sens., vol. 50, no. 1, pp. 212-220, Jan. 2012, doi: 10.1109/TGRS. 2011.2160069.

[7] J.-B. Yan et al., "Ultrawideband FMCW radar for airborne measurements of snow over sea ice and land," IEEE Trans. Geosci. Remote Sens., vol. 55, no. 2, pp. 834-843, Feb. 2017, doi: 10.1109/TGRS.2016. 2616134.

[8] R. Kwok et al., "Airborne surveys of snow depth over Arctic sea ice," J. Geophys. Res., Oceans, vol. 116, no. 11, pp. 1-16, 2011, doi: 10.1029/ 2011JC007371.

[9] F. Rodriguez-Morales et al., "Advanced multifrequency radar instrumentation for polar research," IEEE Trans. Geosci. Remote Sens., vol. 52, no. 5, pp. 2824-2842, May 2014, doi: 10.1109/TGRS.2013. 2266415.

[10] A. Tan, K. Eccleston, I. Platt, I. Woodhead, W. Rack, and J. McCulloch, "The design of a UAV mounted snow depth radar: Results of measurements on Antarctic sea ice," in Proc. IEEE Conf. Antenna Meas. Appl. (CAMA), Dec. 2017, pp. 316-319, doi: 10.1109/CAMA.2017. 8273437.

[11] C. J. Li and H. Ling, "High-resolution, downward-looking radar imaging using a small consumer drone," in Proc. IEEE Int. Symp. Antennas Propag. (APSURSI), vol. 2, Jun./Jul. 2016, pp. 2037-2038, doi: 10.1109/APS.2016.7696725.

[12] C. J. Li and H. Ling, "Synthetic aperture radar imaging using a small consumer drone," in Proc. IEEE Int. Symp. Antennas Propag., Vancouver, BC, Canada, vol. 10, Jul. 2015, pp. 685-686, doi: 10.1109/APS. 2015.7304729.
[13] D. Tarchi, G. Guglieri, M. Vespe, C. Gioia, F. Sermi, and V. Kyovtorov, "Mini-radar system for flying platforms," in Proc. IEEE Int. Workshop Metrol. AeroSpace (MetroAeroSpace), Jun. 2017, pp. 40-44, doi: 10.1109/MetroAeroSpace.2017.7999623.

[14] M. Lort, A. Aguasca, and C. López-Martínez, and T. M. Marín, "Initial evaluation of SAR capabilities in UAV multicopter platforms," IEEE J. Sel. Topics Appl. Earth Observ. Remote Sens., vol. 11, no. 1, pp. 127-140, Jan. 2018, doi: 10.1109/JSTARS.2017.2752418.

[15] J. F. Fitter, A. B. Mccallum, and J. X. Leon, "Development of an unmanned aircraft mounted software defined ground penetrating radar," in Proc. 5th Int. Conf. Geotech. Geophys. Site Characterisation, vol. 5, 2016, pp. 957-962.

[16] D. Šipoš, P. Peter, and D. Gleich, "On drone ground penetrating radar for landmine detection," in Proc. 1st Int. Conf. Landmine: Detection, Clearance Legislations (LDCL), Apr. 2017, pp. 7-10, doi: 10.1109/ LDCL.2017.7976931.

[17] M. A. Yarlequé, S. Alvarez, and H. J. Martínez, "FMCW GPR radar mounted in a mini-UAV for archaeological applications: First analytical and measurement results," in Proc. Int. Conf. Electromagn. Adv. Appl. (ICEAA), Sep. 2017, pp. 1646-1648, doi: 10.1109/ICEAA.2017. 8065606.

[18] P. Kanagaratnam et al., "Ultrawideband radar measurements of thickness of snow over sea ice," IEEE Trans. Geosci. Remote Sens., vol. 45, no. 9 , pp. 2715-2724, Sep. 2007, doi: 10.1109/TGRS.2007.900673.

[19] R.-O. R. Jenssen. (2016). Snow Stratigraphy Measurements With UWB Radar. [Online]. Available: http://hdl.handle.net/10037/11117

[20] R. Zetik, J. Sachs, and R. S. Thomä, "UWB short-range radar sensing-The architecture of a baseband, pseudo-noise UWB radar sensor," IEEE Instrum. Meas. Mag., vol. 10, no. 2, pp. 39-45, Apr. 2007, doi: 10.1109/MIM.2007.364960.

[21] D. Daniels, Ground Penetrating Radar, vol. 1. Stevenage, U.K.: Institution of Electrical Engineers, 2004, pp. 225-237.

[22] M. A. Richards, Fundamentals of Radar Signal Processing. New York, NY, USA: McGraw-Hill, 2015.

[23] F. T. Ulaby, R. K. Moore, and A. K. Fung, Microwave Remote Sensing: Active and Passive, Radar Remote Sensing and Surface Scattering and Emission Theory, vol. II. Reading, MA, USA: Addison-Wesley, 1982.

[24] J. Sachs, R. Herrmann, M. Kmec, M. Helbig, and K. Schilling, "Recent advances and applications of m-sequence based ultra-wideband sensors," in Proc. IEEE Int. Conf. Ultra-Wideband, Sep. 2007, pp. 50-55, doi: 10.1109/ICUWB.2007.4380914.

[25] D. M. Pozar, Microwave Engineering. Hoboken, NJ, USA: Wiley, 2012, pp. $496-521$.

[26] R. K. Panigrahi and A. K. Mishra, "Comparison of Hybrid-polarization with Quad-polarization schemes based on airborne SAR images," in Proc. A Workshop Adv. Antenna Technol., May/Jun. 2010, pp. 1-4, doi: 10.1109/AAT.2010.5545953.

[27] M. Wahab, Y. P. Saputera, and Y. Wahyu, "Design and realization of archimedes spiral antenna for Radar detector at $2-18 \mathrm{GHz}$ frequencies," in Proc. 19th Asia-Pacific Conf. Commun. (APCC), Aug. 2013, pp. 304-309, doi: 10.1109/APCC.2013.6765961.

[28] T. W. Hertel and G. S. Smith, "On the dispersive properties of the conical spiral antenna and its use for pulsed radiation," IEEE Trans. Antennas Propag., vol. 51, no. 7, pp. 1426-1433, Jul. 2003, doi: 10.1109/TAP.2003.813602

[29] A. S. Avdushin, A. V. Ashikhmin, V. V. Negrobov, Y. G. Pasternak, and S. M. Fedorov, "Vivaldi antenna with printed lens in aperture," Microw. Opt. Technol. Lett., vol. 56, no. 2, pp. 369-371, Feb. 2014, doi: 10.1002/mop.28120.

[30] S.-W. Kim and D.-Y. Choi, "Implementation of rectangular slit-inserted ultra-wideband tapered slot antenna," SpringerPlus, vol. 5, p. 1387, Aug. 2016, doi: 10.1186/s40064-016-3033-4

[31] S. M. Conger and D. M. McClung, "Comparison of density cutters for snow profile observations," J. Glaciol., vol. 55, no. 189, pp. 163-169, 2009, doi: 10.3189/002214309788609038.

[32] M. E. Tiuri, A. H. Sihvola, E. Nyfors, and M. Hallikaiken, "The complex dielectric constant of snow at microwave frequencies," IEEE J. Ocean. Eng., vol. 9, no. 5, pp. 377-382, Dec. 1984, doi: 10.1109/JOE. 1984.1145645.

[33] E. Greene, K. Birkeland, K. Elder, I. McCammon, M. Staples, and D. Sharaf, Snow, Weather, and Avalanches: Observation Guidelines for Avalanche Programs in the United States, 3rd ed. Bozeman, MT, USA: American Avalanche Association, 2016.

[34] C. Mätzler, "Potential of microwave remote sensing for assessing critical snow properties," in Proc. Workshop Adv. Techn. Assessment Natural Hazards Mountain Areas, Innsbruck, Austria, 2000, pp. 38-41. 


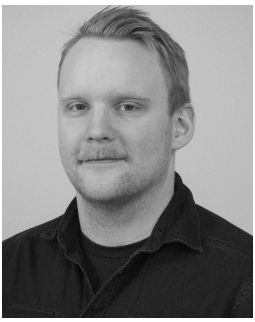

Rolf Ole Rydeng Jenssen received the B.Sc. degree in automation and the M.Sc. degree in applied physics and mathematics, with a focus on snow stratigraphy measurements with ultrawideband radar, from the University of Troms $\varnothing$-Arctic University of Norway, Troms $\varnothing$, Norway, in 2014 and 2016, respectively.

Since 2017, he has been a Ph.D. Fellow with the Centre for Integrated Remote Sensing and Forecasting for Arctic Operations, Troms $\varnothing$, where he is involved in unmanned aerial vehicle remote sensing for Arctic applications such as monitoring of snow and sea ice conditions.

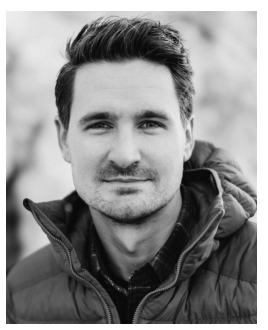

Markus Eckerstorfer received the M.Sc. degree in cartography and geoinformation from the University of Vienna, Austria, in 2017, with a focus on cartographic visualization of snow avalanche risk, and the Ph.D. degree from The University Centre in Svalbard, Longyearbyen, Svalbard and Jan Mayen, in 2018, with a focus on linking regional avalanche activity to controlling meteorological and snowpack factors in Svalbard.

Since 2013, he has been a Research Scientist with the Norut Northern Research Institute, Troms $\varnothing$, Norway, where he has been involved in snow avalanche detection using radar satellite data as well as snowpack characterization using drone-borne sensors.

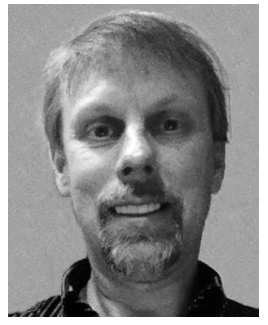

Svein Jacobsen (M'02-SM'07) was born in Lofoten, Norway, in 1958. He received the B.Sc. and M.Sc. degrees and the Ph.D. degree in microwave sensing of the ocean surface from the University of Troms $\varnothing$, Tromsø, Norway, in 1983, 1985, and 1988, respectively.

From 1985 to 1986, he was a Researcher with Information Control Ltd., Asker, Norway, where he was involved in space-borne observation platforms for the earth-probing satellite ERS-1. From 1989 to 1992, he was a Research Scientist with the Norwegian Research Council for Science and Humanities, Oslo, Norway, where he was involved in nonlinear mapping of the ocean surface by means of synthetic aperture imaging radar. From 2000 to 2001, he did a research sabbatical at the University of California at San Francisco, San Francisco, CA, USA, where he investigated the use of multiband microwave radiometry for temperature measurement in the human body. Since 2001, he has been a Professor of electrical engineering with the Department of Physics and Technology, University of Troms $\emptyset$ - The Arctic University of Norway, Troms $\varnothing$. His current research interests include thermal medicine, development of active and passive microwave systems, applicators for diagnostic and therapeutic applications in the human body, development of miniature unmanned aerial vehicle-mounted ultrawideband radars for various remote sensing applications including snowpack stratigraphy for hardness investigation and weak layer detection. 